\title{
Cultivar mixture improved yield and water use efficiency via optimization of root properties and biomass distribution in maize (Zea mays L.)
}

\author{
Xiaolin Wang ${ }^{1,2}$, Yinglong Chen ${ }^{2,3}$, Suiqi Zhang ${ }^{2,3 *}$ \\ ${ }^{1}$ College of Life Science, Yulin University, Chongwen Road No.4, Yulin, Shannxi, 719000, PR China, ${ }^{2}$ State Key Laboratory of Soil Erosion \\ and Dryland Farming on the Loess Plateau, Chinese Academy of Sciences and Ministry of Water Resources, Xinong Road No. 26, Yangling, \\ Shaanxi, 712100, PR China, ${ }^{3}$ State Key Laboratory of Soil Erosion and Dryland Farming on the Loess Plateau, Northwest A\&F University, \\ Xinong Road No.26, Yangling, Shaanxi, 712100, PR China
}

\section{A B S T R A C T}

\begin{abstract}
Use of chemical fertilizer and high-density plantings has increased maize productivity in semi-arid regions. With high-density planting, interaction among individuals may impede or improve sustainable yield and resources use, the elucidation of its effects requires more study. A 2-year field experiment was conducted to evaluate the effects of interaction between two mixed maize cultivars on root properties, biomass distribution and water use. Root biomass and surface area decreased, concomitantly, root hydraulic conductivity was improved because root length density in the $0-30 \mathrm{~cm}$ soil layer increased in the mixed crop plots. Lower root to shoot ratios resulted from positive interaction of the two mixed maize cultivars. Consequently, mixed planting interaction increased the harvest index under high-planting density. Finally, grain yield increased by $2.6 \%-15.6 \%$ and water use efficiency by $4.7 \%-18.3 \%$ with a disproportionate trend in different mixed planting densities compared with that of solitary crops. Maize yield and water use efficiency were improved under the same-high mixed planting density because of the improvement of root properties and the optimization of biomass distribution, in semi-arid region of China.
\end{abstract}

Keywords: Maize cultivars mixture; Root morphology; Root hydraulic conductivity; Semi-arid region

\section{INTRODUCTION}

Maize yield and water use efficiency (WUE) were stagnated because of soil degeneration and inefficient resource competition after continuous massive chemical fertilizer input and high-density planting (Ju et al., 2009). Mixed competition as an interaction between individuals was brought about by a shared requirement for limited resources (Zhai et al., 2011), such as soil moisture and nutrients, especially under drought condition (Kiaer et al., 2009). Therefore, cultivar mixtures could be an effective agro-technological option for stable maize yield (Kiaer et al., 2009; Zhai et al., 2011), because of its heterosis, open pollination, and great capacity to adjust to biotic and abiotic stresses (Fang et al., 2014). Based on the different morphological traits of mixed varieties, cultivar mixtures could also offer benefits while compensating for weaknesses of the component varieties (Kiaer et al., 2009). Moreover, mixtures inevitably result in competition between the cultivars components. However, Zhang et al. (1999) reported there was a negative correlation between crop competitiveness and productivity, and reducing competition could increase grain yield. Therefore, the level of competitive interaction of mixed components required to achieve the desired growth traits is vital information and needs further verification, with the goal of stable increase in yield compared with pure sowing (Malezieux et al., 2009; Kiaer et al., 2012).

Prediction of growth traits of cultivars in a mixture could facilitate the identification of the best cultivars for the formation of the mixture system (Lopez and Mundt, 2000). Previous study indicated that the high biological efficiency of mixtures might be attributable to the differences in cultivar growth cycles and root architecture (Radicetti et al., 2012). Conclusions indicated that either greater competitiveness could improve grain yield or that there was no relationship between competitiveness and final yield

\footnotetext{
${ }^{*}$ Corresponding author:

Suiqi Zhang, State Key Laboratory of Soil Erosion and Dryland Farming on the Loess Plateau, Northwest A\&F University, Chinese Academy of Sciences and Ministry of Water Resources, Xinong Road No.26, Yangling, Shaanxi, 712100, PR China. E-mail: sqzhang@ms.iswc.ac.cn
}

Received: 21 August 2016; $\quad$ Revised: 14 February 2017; $\quad$ Accepted: 16 February 2017; Published Online: 25 February 2017 
(Lopez and Mundt, 2000; Radicetti et al., 2012). Song et al. (2009) reported that modern wheat cultivars with small root systems were less competitive, but more productive, than older cultivars with large root systems, which was consistent with previous findings because winter wheat cultivars with smaller root systems in the upper soil profile could obtain a significant increase in WUE and harvest index (HI) (Fang et al., 2014). These results indicated that drought-resistance breeding had unintentionally reduced the cultivars' competitiveness and increased grain yield via a reduction in the root to shoot ratio and tightly stretched roots, and higher $\mathrm{HI}$ resulted from reduced competitiveness (Donald 1968; Zhang et al., 1999). Therefore, reduced root competitiveness may increase WUE and grain yield (Ma et al., 2008), but further more studies are needed to clarify these phenomena.

To date, most studies of mixtures have concentrated on the advantages of the mixture in terms of yield (Lopez and Mundt, 2000). However, in semi-arid regions, such as the Loess Plateau of China, which experiences limit and unpredictable season rainfall, high yield and WUE are two equally important goals for mixtures (Fang et al., 2014). Crop traits were associated with competitiveness, but information on the competitiveness of maize cultivars was lacking (Zhai et al., 2011). With the main objective of comparing the variability of biomass distribution, root growth and root hydraulic conductivity of two maize cultivars in a mixture, this study was arranged to verify the hypothesis that increase of maize yield and WUE in different mixtures might result from the optimization of maize root properties and biomass distribution, in semiarid region of China.

\section{MATERIALS AND METHODS}

\section{Field experiment site}

Field experiments were performed on spring maize during 2011 and 2012 at the Chang Wu Agro-ecological Experimental Station ( $35^{\circ} 1230^{\prime}$ N, $107^{\circ} 40^{\prime} 30^{\prime \prime} \mathrm{E}$, altitude $1200 \mathrm{~m}$ ) of the Chinese Academy of Sciences, Shaanxi Province. The site was located in the south-central region of the Loess Plateau, as a semi-arid farming region in northwestern China. Soil was classified as Cumuli-Ustic Isohumosol according to the Chinese Soil Taxonomy System (Gong et al., 2007), with a pH of 8.4 and a bulk density of $1.3 \mathrm{~g} \mathrm{~cm}^{-3}$ in $0-20 \mathrm{~cm}$ soil profile. Organic matter, total nitrogen, available phosphorus and available potassium contents were $11.8 \mathrm{~g} \mathrm{~kg}^{-1}, 0.9 \mathrm{~g} \mathrm{~kg}^{-1}, 14.4 \mathrm{mg} \mathrm{kg}^{-1}$, and $144.6 \mathrm{mg} \mathrm{kg}^{-1}$ in $0-20 \mathrm{~cm}$ soil profile, respectively. The experimental site had a temperate, semi-humid, and semiarid monsoon climate, 30-year mean daily temperature and annual precipitation was $9.1^{\circ} \mathrm{C}$ and $577.0 \mathrm{~mm}$, approximately $80 \%$ of the rainfall occurs from May to September (maize growing period).

\section{Cultivars characteristics}

Zhengdan 958 (Z958, represented herein by A) is a modern maize cultivar that has been widely sowed in northern China; it is characterized by tolerance to highdensity conditions, as well as drought, lodging, and disease resistance.

Shendan 16 (S16, represented herein by B) is an old variety, being a taller plant shoot with stocky stems, wide and thick leaves, and larger root systems. As such, these properties require more energy and resources to achieve normal development. Unfortunately, S16 often experiences lodging and unexpected yield loss in the semi-arid region of Loess Plateau.

\section{Mixed pattern design and plot arrangement}

Field experiment contained two maize cultivars (Z958 and S16), two cultivation methods (mixed crop and monoculture), and two planting densities (45,000 and 75,000 plants ha ${ }^{-1}$, represented as 1 and 2, respectively, Fig. 1). Seeds were sown on April 20, 24 and harvested on September 15, 20 in 2011 and 2012, respectively. All of the plots were $5 \times 5 \mathrm{~m}\left(25 \mathrm{~m}^{2}\right)$ and arranged in a split block design with three replicates. Each plot contained 10 rows $(0.5 \mathrm{~m}$ row space and $5 \mathrm{~m}$ length), mixed systems of Z958 and S16 with a row ratio of $6: 4(\mathrm{~A}: \mathrm{B}=6: 4)$ were established and adjacent rows contained different maize cultivar. The two maize cultivars were sown in alternating two rows at two densities, with basal fertilizer of $240 \mathrm{~kg} \mathrm{~N} \mathrm{ha}^{-1}$ as urea, $120 \mathrm{~kg} \mathrm{P}_{2} \mathrm{O}_{5} \mathrm{ha}^{-1}$ as superphosphate, and $90 \mathrm{~kg} \mathrm{~K}_{2} \mathrm{O} \mathrm{ha}^{-1}$ as potassium sulfate was scattered uniformly in each plot then ploughed under to the $0-30 \mathrm{~cm}$ soil layer. At the

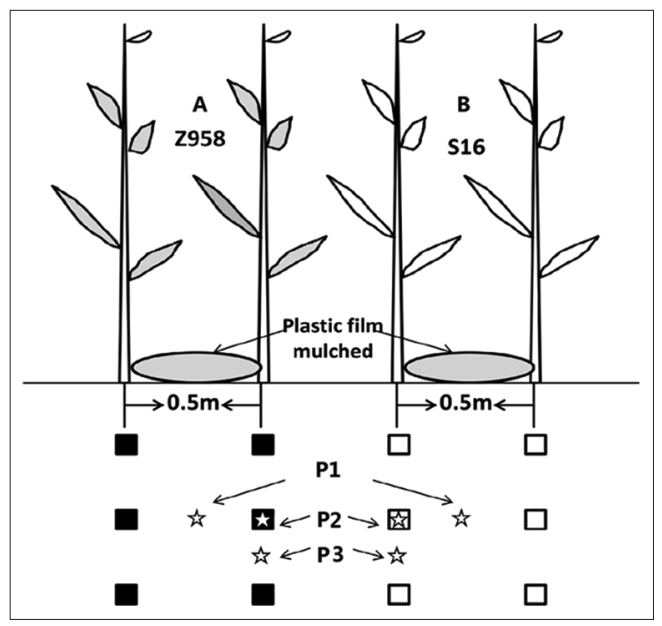

Fig 1. Mixed planting strips of two maize cultivars and root sample positions, distances between rows was indicated, three root sample positions ( $(2)$ ) was presented as (P1) at the inter-row of maize, (P2) at the intra-row of maize and (P3) at the maize plant. 
elongation stage (45 days after sowing, DAS), additional N as urea at $90 \mathrm{~kg} \mathrm{ha}^{-1}$ was ditch applied between the maize rows to a $20 \mathrm{~cm}$ depth. Four mixed-crop treatments were abbreviated as A1B1, A1B2, A2B1, and A2B2 for Z958 and S16. Sole cropping of the two maize cultivars at both planting densities (CK-A1, CK-A2, CK-B1, and CK-B2) served as controls.

\section{Above-ground biomass and root samples collection} Above-ground biomass samples were collected from three adjacent plants with similar size (visually assessed) from each plot at the physiological mature stage to investigate the changes in the root to shoot ratio (Palta et al., 2011). Aboveground portions were inactivated for $30 \mathrm{~min}$ at $105^{\circ} \mathrm{C}$, dried to a constant weight at $80^{\circ} \mathrm{C}$, and weighed to determine shoot biomass.

Soil cores were sampled at physiological maturity with a root auger to minimize damage to the plots and examine root morphology in detail. The soil cores $(9 \mathrm{~cm}$ in diameter and $10 \mathrm{~cm}$ depth) were collected at $10 \mathrm{~cm}$ intervals to a maximum depth of $40 \mathrm{~cm}$, which were positioned at the inter- row, the intra-row and at the plant (Fig. 1). Soil samples were washed in a plastic basket packed with yarn to obtain fresh root samples, which were scanned (Epson Perfection V700, Seiko Epson Crop, Suwa, Japan) and analyzed using WinRHIZO (Regent Instrument Inc., Quebec, Canada) to determine the root length density (RLD) and root surface area (RSA). Furthermore, root samples were dried to a constant weight at $80^{\circ} \mathrm{C}$ for total root weight (RW) calculation.

\section{Root hydraulic conductivity measurement}

Root hydraulic conductivity ( $\mathrm{Lp}_{\mathrm{r}}$ ) from 85 to 130 DAS was measured for individual maize plant using a High Pressure Flow Meter (HPFM, Dynamax Inc., Houston, TX77099, and USA). Three plants with similar size were selected, and their stems were cut at a height of $15 \mathrm{~cm}$ above the ground. It was important that the stem section be beveled before installed into the vacuum spiral chamber that linked to HPFM via a plastic vacuum pipe through which water flows into the stem section. HPFM was connected to a nitrogen tank and a computer with HPFM analysis software. During the conductivity measurements, water moved to the roots through the stem section, while air pressure increased from 0 to $500 K p a$, the computer recorded the changes in water flow rate and air pressure, and calculated the $\mathrm{Lp}_{\mathrm{r}}$ based on the dynamic change in water flow rate and air pressure.

\section{Grain yield and water consumption}

Grain yield (GY) was estimated from all consecutive plants within a $5.0 \mathrm{~m}^{2}$ section of the middle two rows in each plot. All spikes were manually collected and grains adjusted to $15 \%$ moisture as GY. Soil water storage (SWS), evapotranspiration (ET), root to shoot rate (RSR) and harvest index (HI) in the mixed cropping system were calculated using the following formulas (Zhang et al., 1999; Fang et al., 2014):

$$
\begin{aligned}
& E T=S W S+P \\
& S W S=S B D \times S D \times S W C \\
& R S R=\frac{R B}{S B} \\
& H I=\frac{G B}{G B+S B}
\end{aligned}
$$

Where SWS is soil water storage, $\mathrm{P}$ is precipitation during the maize growing season, SBD is soil bulk density, SD is soil depth, and SWC is soil water content, RB is root biomass, $\mathrm{SB}$ is shoot biomass, and GB is grain biomass.

SWC was measured gravimetrically at sowing and harvested stages in the two study years. Soil samples were collected at $10 \mathrm{~cm}$ intervals over a depth of $0-100 \mathrm{~cm}$ and at $20 \mathrm{~cm}$ intervals over a depth of 100-200 cm. Soil samples were weighed before and after drying at $105^{\circ} \mathrm{C}$ for $24 \mathrm{~h}$ to determine SWC. Mean monthly precipitation and temperature during the two growth periods were recorded using the local automatic weather station, as shown in Fig. 2.

\section{Data analysis}

One-way analysis of variance (ANOVA) at $P<0.05$ was used to compare the means among the mixed treatments in SPSS Statistics 17. The means exhibiting significant differences between the two mixed maize cultivars were separated using the least significant difference (LSD) test at $P<0.05$.

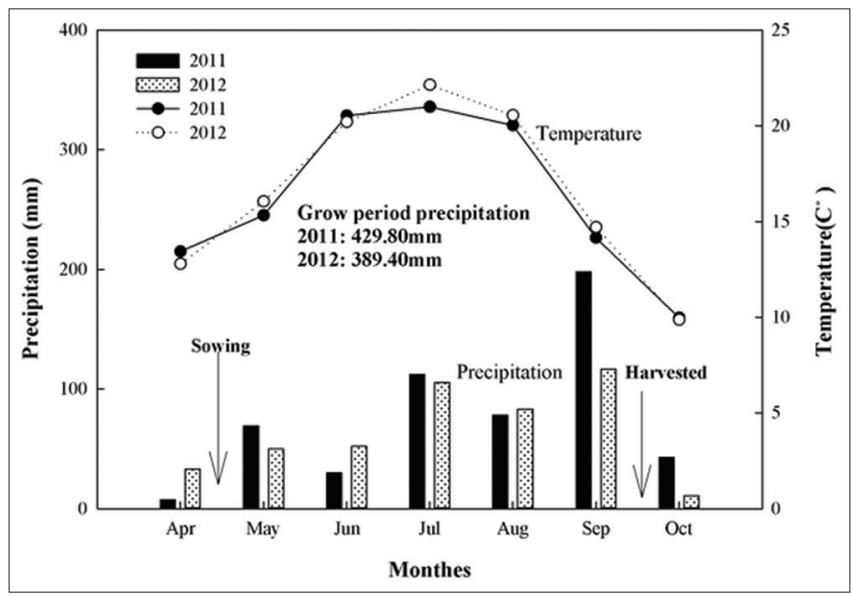

Fig 2. Monthly precipitation and temperature during the two growth seasons, the histogram showed the precipitation over two years, 2011 (black histograms), 2012 (dots histograms), and average temperature of two years showed as 2011 (close circle line) and 2012 (open circle line). 


\section{RESULTS AND DISCUSSTION}

Genotypic variation for root characteristics and function can be exploited to improve grain yield and WUE under water-limited conditions (Palta et al., 2011), with an increase in yield generally accomplished by small root systems. Modern wheat cultivars with small root systems were less competitive but more productivity than old cultivars with large root systems (Zhai et al., 2011). Root systems of the mixed components responded strongly to soil resource competition by altering root morphological traits (Smith et al., 2005), such as root dry weight, root length or surface area, and physiological plasticity (Malezieux et al., 2009). In the present study, a mixture of maize cultivars promoted growth of the upper $(0-20 \mathrm{~cm})$ fine roots as shown in the RLD increase (Fig. 3). Differences of RLD in the four mixed systems indicated that mixed planting densities adjusted vertical distribution of RLD. In A1B1, A1B2, and A2B1, increase of RLD was evident in $0-20 \mathrm{~cm}$ soil profile. In A2B2, RLD of mixed maize cultivars significantly increased $(P<0.05)$ in the $0-20 \mathrm{~cm}$ soil layer compared with that of the pure sowing, and a larger RLD occurred in 2012. High mixed planting density significantly increased $(P<0.05)$ the RLD of Z958, and restricted the RLD of S16. RLD of both maize cultivars was suppressed as the mixed planting density of one component increased. Competitive interaction in mixed maize cultivars suppressed root radial growth as evidenced by an increase in RLD combined with a decrease in total RSA and RW. RW and RSA of Z958 decreased as the mixed density of S16 increased. Root growth of the modern maize cultivar showed more variability in the mixture (Table 1). RW of Z958 was suppressed as the mixed density of S16 increased with respect to that of pure stands. RW of S16 increased in lower mixed planting density and showed no significant changes caused by the effect of Z958. Therefore, this provides evidence of the vigorous spreading of the fibrous roots and heralds a higher RLD in maize cultivar mixed systems. RLD and RSA of both cultivars increased in the mixed system, especially in 2012 because of the lower precipitation, which resulted in intensive root competition for soil water. Competition for soil water was seen not only in the morphological and anatomical traits, but also in the functional features of the root systems in mixed crops (Carvalho and Foulkes, 2011). Estimation of $\mathrm{Lp}_{\mathrm{r}}$ is a significant process given the interconnectedness of the root system architecture with water transfer (Roose and Fowler, 2004; Palta et al., 2011). In our present research, $\mathrm{Lp}_{\mathrm{r}}$ of Z958 and S16 increased significantly $(P<0.05)$ with lower precipitation (14\% lower than 30-year average). Meanwhile, Z958 suppressed the Lp of S16 when precipitation was $11.6 \%$ higher than the 30-year average during 85-105 DAS (Fig. 4). The improved $\mathrm{Lp}_{\mathrm{r}}$ aided in competition for water and nutrients (Smith and Roberts, 2003), drove root water uptake, particularly for the roots near the regions of upper soil layer (Palta et al., 2011), and then fulfilled the demand for water, especially during the grain filling stage of maize (Xia et al., 2013). The components of the mixture may be complementary in a spatial sense by exploiting water and nutrients in the soil layer with their root systems, which had different morphological and functional traits (Malezieux et al., 2009; Song et al., 2009).

Increased plant density is used not only to produce higher yield, but also for improving plant-to-plant availability (Lopez and Mundt, 2000). Damgaard et al. (2002) confirmed that at higher planting density, soil resources were limited for single plants, shoot biomass was reduced, root growth was suppressed, and the number of small individuals increased (Jiang et al., 2013), heralding yield loss in the single plant. Competitive interaction among individuals in high-density plantings asymptotically affects

Table 1: Relative changes in the root weight (RW) and root surface area (RSA)

\begin{tabular}{|c|c|c|c|c|c|c|}
\hline \multirow[t]{2}{*}{ Treatments } & \multicolumn{2}{|c|}{ RW (g) } & \multicolumn{2}{|c|}{ RSA $\left(\mathrm{cm}^{2}\right)$} & \multicolumn{2}{|c|}{ Mean } \\
\hline & 2011 & 2012 & 2011 & 2012 & RW (g) & $\mathrm{RSA}\left(\mathrm{cm}^{2}\right)$ \\
\hline A1B1-A1 & $18.62 \mathrm{ab}$ & $14.92 b$ & $2172.28 a$ & $3006.94 b$ & $16.77 a b$ & $2589.61 a b$ \\
\hline A1B2-A1 & $15.18 a b$ & $15.48 a b$ & $1344.67 \mathrm{~b}$ & $4204.10 a$ & $15.33 b$ & $2774.39 a$ \\
\hline CK-A1 & $19.85 a$ & $18.57 a$ & $1794.41 \mathrm{ab}$ & $3221.60 \mathrm{~b}$ & $19.21 \mathrm{a}$ & $2508.01 b$ \\
\hline A1B1-B1 & 18.19ab & $18.66 b$ & $1469.08 b$ & $2828.57 b$ & $18.42 \mathrm{ab}$ & $2148.83 b$ \\
\hline A2B1-B1 & $15.84 b$ & $22.68 \mathrm{a}$ & 1543.24ab & $3129.21 a$ & $19.26 \mathrm{a}$ & $2336.23 a b$ \\
\hline CK-B1 & $20.17 a$ & $13.60 c$ & $1752.82 a$ & $3100.64 a$ & $16.88 \mathrm{~b}$ & $2426.73 a$ \\
\hline A2B1-A2 & $8.82 b$ & $11.65 a$ & $1568.78 a b$ & $3826.20 a$ & $10.24 a$ & $2697.50 a$ \\
\hline A2B2-A2 & $9.57 a b$ & $8.01 a$ & $1469.05 b$ & $2647.75 b$ & $8.79 b$ & $2058.40 b$ \\
\hline CK-A2 & $11.17 \mathrm{a}$ & $10.09 a$ & $1967.27 a$ & $3345.10 a b$ & $10.63 a$ & $2656.19 a$ \\
\hline A1B2-B2 & $10.24 a b$ & $6.89 a$ & 1417.29ab & $2609.17 b$ & $8.57 a$ & 2013.23a \\
\hline A2B2-B2 & $8.88 b$ & $9.79 a$ & $1511.03 a$ & $2718.07 a b$ & $9.34 a$ & $2114.55 a$ \\
\hline CK-B2 & $11.46 a$ & $8.14 a b$ & $1382.56 b$ & $2994.33 a$ & $9.80 a$ & $2188.45 a$ \\
\hline
\end{tabular}

a: The different letters in a column indicate significant differences among the mixed systems and pure stands with the same planting density at $P=0.05,{ }^{*} R W$ and $R S A$ indicate the total root dry weight and surface area at the depth of $100 \mathrm{~cm}$ soil profile, the significant differences were among the mixed and pure stands, which had the same cultivar and planting density, the data represent 2011 and 2012 as the mean of two years under the same treatments 


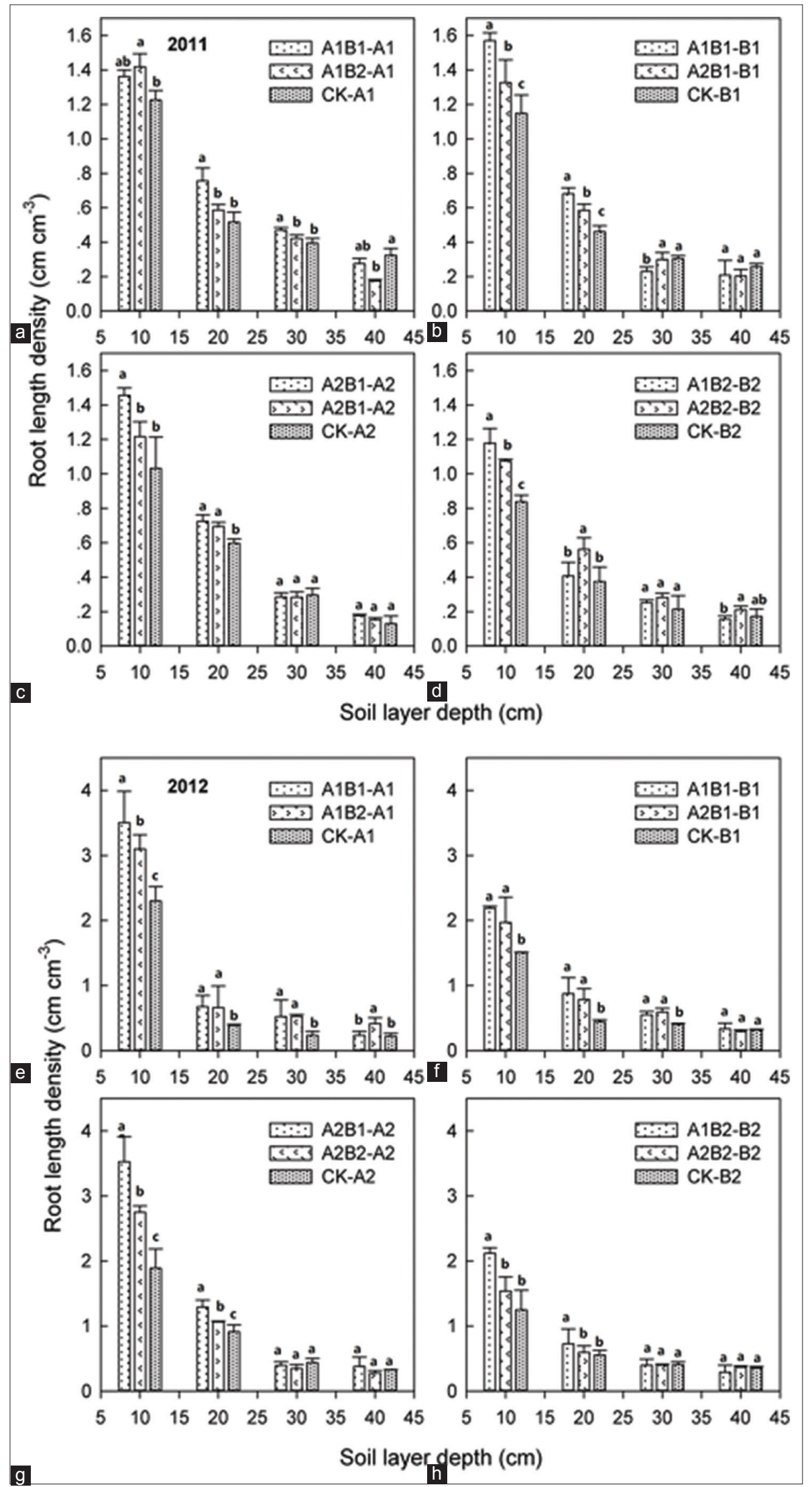

Fig 3. The differences in roots length density (RLD) between the mixed planting systems and pure stands, the different letters above the histograms indicate the significant difference between mixed planting systems and pure stands with the same density and soil layer at $P=0.05,2011(\mathrm{a}, \mathrm{b}$, $c$ and d), 2012 (e, f, g and h). 


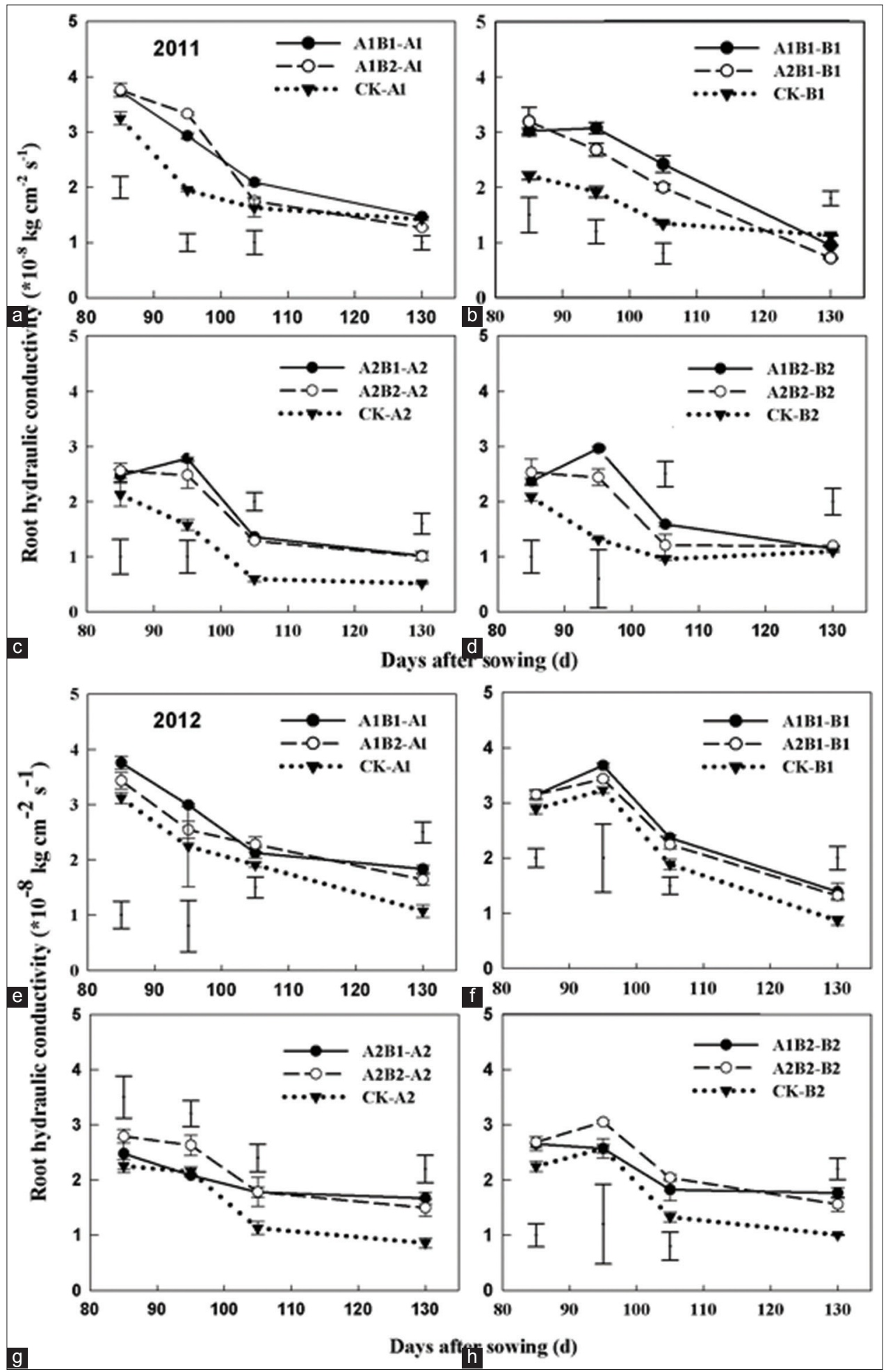

Fig 4. Dynamic variation in the root hydraulic conductivity (Lpr), the four panels indicated the comparison between dynamic changes of $L p_{r}$ of one maize cultivar under mixed planting and pure stand in two densities, respectively. The bars are the LSD at $P=0.05,2011$ (a, b, c and d), $2012(e, f, g$ and $h)$.

the accumulation of vegetative and reproductive biomass (Tetio-Kagho and Gardner, 1988) and leads to a reduction in the performance of the competing individuals (zhai et al., 2011). Given the competition among cultivars within a mixed system, maize cultivars respond more favorably to an increase in shoot biomass and a moderate canopy structure (Damgaard et al., 2002; Asim et al., 2013), which can intercept more active radiation and efficiently prepare 
plants for grain production (Gao et al., 2013). A deep and bushy root distribution and corresponding shoot growth exhibit a positive correlation with grain yield in semi-arid region (Xia et al., 2013). Mixed planting density and maize morphological traits could affect the dynamic change in shoot and root growth (Gao et al., 2013; Xia et al., 2013). In our results, RSR of mixed maize cultivars was significantly suppressed $(P<0.05)$ at higher mixed planting density (Fig. 5). Given the different morphological traits, S16 suppressed the RSR of Z958, but under moderate drought condition, this restriction was remitted to Z958 and S16. Mixed cropping interaction still limited maize root thickening, improved shoot canopy, and led to a significant decrease in RSR. Because of the variation in RSR associated with mixed planting density, maize cultivar mixed cropping had the potential to adjust above- and below-ground growth for high production compared to the monoculture. Previous research suggested that lower RSR was beneficial for decreasing water consumption by roots and for the efficient water use by leaves (Fang et al., 2014). Furthermore, lower carbon invested in root biomass probably enabled more carbon to be assimilated by the shoots. Consistent with the results in a mixture of two winter wheat cultivars, lower RSR had a greater WUE than that of the monoculture in a semi-arid region of China (Zhang et al., 1999; Fang et al., 2014).

$\mathrm{HI}$ reflects the photosynthate allocation into maize grains and vegetative parts (Donald, 1968). An increase in HI indicates an increase in grain production and the adaptation of crop plants to growing environments (Sinclair, 1998). In the mixed system, HI largely related to the planting density of mixed maize cultivars, and was more closely associated with the final grain yield than shoot biomass (Echarte et al., 2011). However, Cox (1996) reported that only optimizing plant density did not efficiently improve the HI. Our results revealed that $\mathrm{HI}$ increased significantly $(P<0.05)$ under maize mixed planting with the same density (Fig. 6), especially at the higher planting densities, where Z958 exhibited a higher HI than S16, A similar trend of continual improvement of $\mathrm{HI}$ in the mixed cropping systems was observed over two years, especially in A2B2. Plant density combined with cultivar mixtures showed great potential to improve HI (Hay, 1995). Maize cultivar mixtures exhibited adaptations to current intensive cultivation practices, all these adaptations ultimately resulted in substantial increases in grain yield (Temesgenet al., 2015).

Mixed components generally exhibit a different yield potential and competitive capacity for water and nutrients (Hu et al., 2016), and competitive interaction in a mixture could realize the sustainable yield and efficient resources use in dry land farming via improving the utilization of precipitation and maintaining soil water balance (Lin et al., 2014). WUE and yield advantage is demonstrated by rationally combined crops or cultivars (Mushagalusa et al., 2008), which must be provided with self-adjustment and weak competitiveness in the mixed microenvironment (Zhai et al., 2011; Lithourgidis et al., 2011). Our research showed that grain yield increased from 11.5 to $14.2\left(\times 10^{3} \mathrm{~kg} \mathrm{ha}^{-1}\right)$

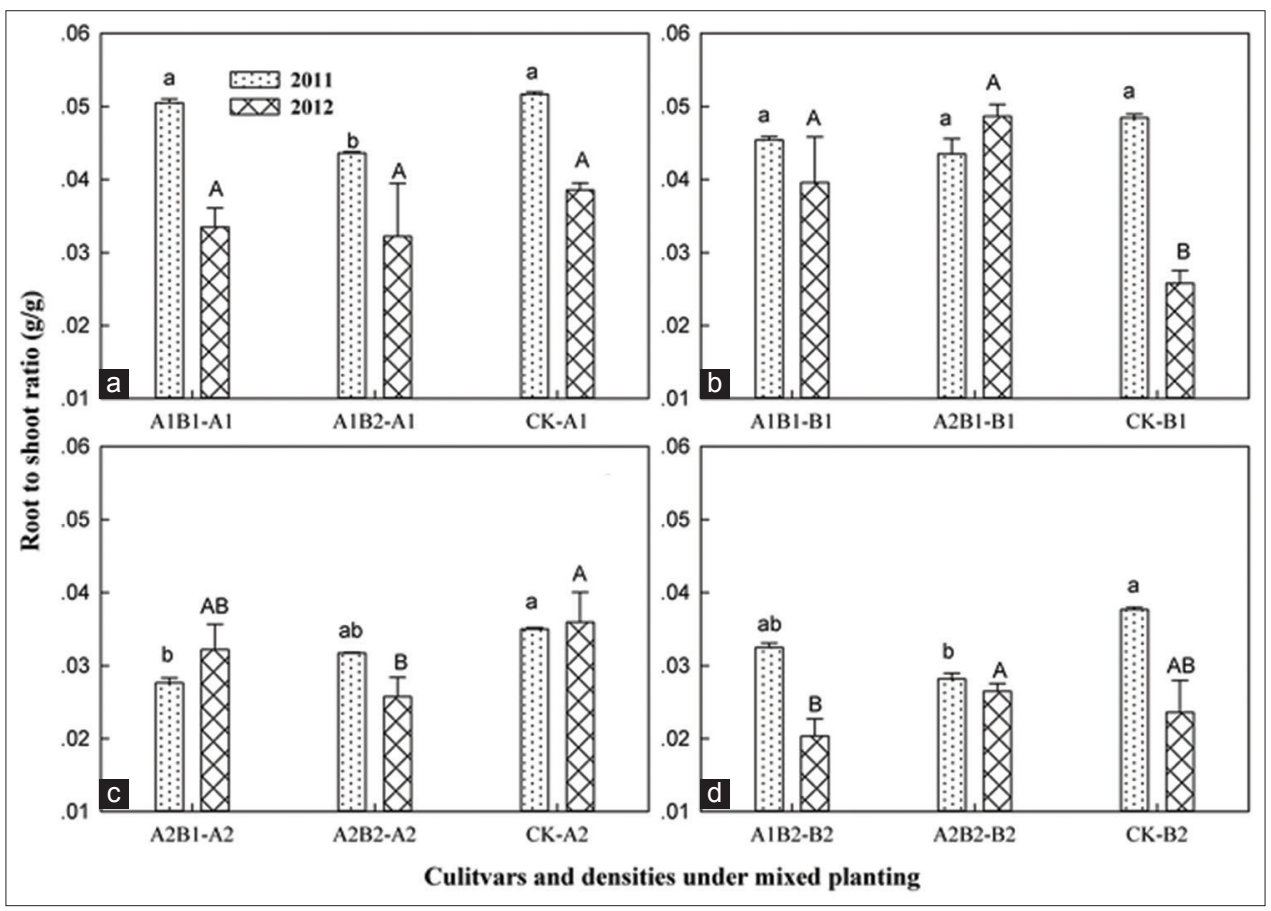

Fig 5. (a-d) The effects of mixed cultivars interaction on root to shoot rate (RSR), different letters above the histograms indicate the significant differences among the mixed cropping systems and controls, a/b indicates the significance at 2011 and $A / B$ indicates the significance at $2012(P=0.05)$. 
and WUE increased from 33.0-40.3 $\left(\mathrm{kg} \mathrm{ha}^{-1} \mathrm{~mm}^{-1}\right)$ in the mixed crop scenario over two years (Table 2), by the range of 5-7\% and 8-14\% higher, respectively, than that in pure stands. Population-level yield and WUE significantly increased in $\mathrm{A} 1 \mathrm{~B} 1$ and $\mathrm{A} 2 \mathrm{~B} 2$, which of $\mathrm{A} 1 \mathrm{~B} 2$ and $\mathrm{A} 2 \mathrm{~B} 1$ occupied the middle space comparing with that of sole cultivation, and exhibited a significant increase in 2012 compared with 2011. Over two years, grain yield of Z958 and S16 positively increased by $2.2-14.6 \%$ and $2.9-16.7 \%$ in mixed cropping systems. WUE of Z958 and S16 obtained a positive increase by $6.2-17.3 \%$ and $3.1-19.3 \%$.
S16 had great competitive advantage for soil water over Z958 in a mixture because of its higher root function. The main limiting factor to yield and WUE was the mixed plant density, similar and high mixed density exhibited a yield and WUE advantage. Furthermore, mild drought stimulated the mixed cultivars inter-competition for soil resources and improved root properties and biomass allocation (Zajac et al., 2014; Liang et al., 2016). In the end, the yield and WUE of both of Z958 and S16 increased by an average of 9.6 and $11.5 \%$, respectively (Table 3). Based on efficient rainfall capture, soil water uptake was improved

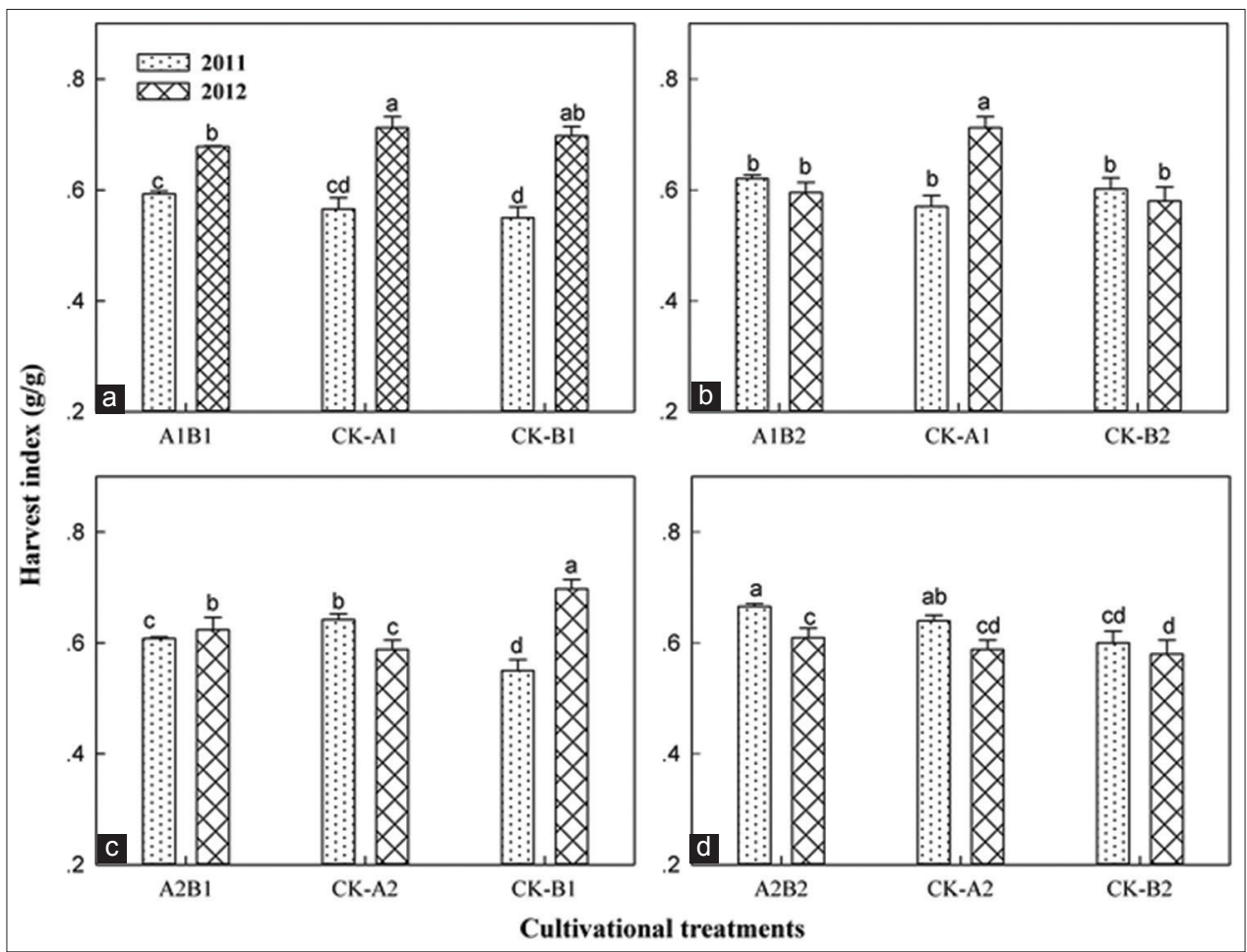

Fig 6. Changes of harvest index $(\mathrm{HI})$ in the mixed cultivated systems over two growing seasons, the four panels (a, b, c, d) list $\mathrm{HI}$ of four mixed cropping systems compared with controls which planted with the same density. The different letters above the histograms indicate the significant difference among the mixed systems and controls at $P=0.05$.

Table 2: Variation of grain yield (GY), evapotranspiration (ET), and water use efficiency (WUE)

\begin{tabular}{|c|c|c|c|c|c|c|}
\hline \multirow[t]{2}{*}{ Treatments } & \multicolumn{2}{|c|}{ GY $\left(\times 10^{3}, \mathrm{~kg} \cdot \mathrm{ha}-1\right)$} & \multicolumn{2}{|c|}{ ET $(\mathrm{mm})$} & \multicolumn{2}{|c|}{ WUE (kg. ha-1 $\left.\mathrm{mm}^{-1}\right)$} \\
\hline & 2011 & 2012 & 2011 & 2012 & 2011 & 2012 \\
\hline A1B1 & $9.13 d$ & $13.85 a b$ & $353.14 a$ & $345.34 b$ & $25.84 \mathrm{c}$ & $40.10 a b$ \\
\hline A1B2 & $11.71 \mathrm{bc}$ & $14.27 a b$ & $369.74 a$ & $353.89 b$ & $31.66 \mathrm{~b}$ & $40.61 a b$ \\
\hline A2B1 & $10.30 \mathrm{~cd}$ & $14.67 a$ & $350.94 a$ & $368.97 a b$ & $29.35 b$ & $39.76 a b$ \\
\hline A2B2 & $12.92 b$ & $15.42 a$ & $352.87 a$ & $351.01 b$ & $36.62 a b$ & $43.93 a$ \\
\hline CK-A1 & $9.09 d$ & $11.45 b$ & $347.99 a$ & $361.49 a b$ & $26.12 \mathrm{c}$ & $32.69 \mathrm{c}$ \\
\hline CK-B1 & $9.11 d$ & $12.57 b$ & $360.06 a$ & $373.98 a b$ & $25.31 \mathrm{c}$ & $33.61 \mathrm{c}$ \\
\hline CK-A2 & $14.13 a$ & $14.35 a b$ & $368.47 a$ & $383.10 a$ & $38.36 a$ & $37.45 b$ \\
\hline CK-B2 & $12.12 b$ & $14.99 a$ & $345.14 a$ & $380.48 a$ & $35.11 a b$ & $39.39 a b$ \\
\hline \multicolumn{7}{|c|}{ Resource of Variation } \\
\hline Density (D) & * & & NS & & * & \\
\hline Year $(\mathrm{Y})$ & * & & NS & & * & \\
\hline$D \times Y$ & * & & NS & & * & \\
\hline
\end{tabular}

The different letters in a column indicate the significant differences among the mixed systems and sole crops in a single year and among the means over two years at $P=0.05,{ }^{*}$ indicate the significant differences among all the treatments and between the two years at $P=0.05$, which had the same planting density, NS, not significant 
Wang, et al:: Cultivar mixture improved grain yield and WUE

Table 3: Increase rate of GY and WUE in two growing seasons

\begin{tabular}{|c|c|c|c|c|c|c|c|c|}
\hline \multirow[t]{2}{*}{ Increase rate (\%) } & \multicolumn{4}{|c|}{2011} & \multicolumn{4}{|c|}{2012} \\
\hline & CK-A1 & CK-B1 & CK-A2 & CK-B2 & CK-A1 & CK-B1 & CK-A2 & CK-B2 \\
\hline \multicolumn{9}{|l|}{ GY } \\
\hline A1B1 & 0.44 & 0.22 & $\cdots$ & $\ldots$ & 11.25 & 10.18 & $\cdots$ & $\ldots$ \\
\hline A1B2 & 28.82 & $\ldots$ & $\ldots$ & -3.38 & 14.62 & $\ldots$ & $\ldots$ & -4.80 \\
\hline A2B1 & $\ldots$ & 13.06 & -27.11 & $\ldots$ & $\ldots$ & 16.71 & 2.23 & $\ldots$ \\
\hline A2B2 & $\cdots$ & $\ldots$ & -8.56 & 6.60 & & & 7.46 & 2.87 \\
\hline \multicolumn{9}{|l|}{ WUE } \\
\hline A1B1 & -1.07 & 2.09 & $\cdots$ & $\ldots$ & -6.07 & 19.31 & $\cdots$ & $\ldots$ \\
\hline A1B2 & 21.21 & $\ldots$ & $\ldots$ & -9.83 & -4.87 & $\ldots$ & $\ldots$ & 3.10 \\
\hline A2B1 & $\ldots$ & 15.96 & -23.49 & $\ldots$ & $\ldots$ & 18.30 & 6.17 & $\ldots$ \\
\hline A2B2 & $\ldots$ & $\ldots$ & -4.54 & 4.30 & 0 & प & 17.30 & 11.53 \\
\hline
\end{tabular}

The value represents the increase rate (\%) of maize cultivar in a mixture compared to that in pure stand with the same density over two years, positive values indicate the positive increase of maize cultivar's yield and WUE, and vice-versa to negative values, the sum of increase rate of two maize cultivars under mixed copping indicated the yield and WUE advantage of mixed system or not

via rhizosphere interaction in the mixed cropping of the old and modern wheat cultivars, and WUE was increased in the mixed systems (Zhai et al., 2011; Fang et al., 2014). We obtained a consistent trend of yield and WUE increase in the maize cultivar mixture. However, some uncertainty remains regarding the yield potential in mixed systems at each planting density and dry matter production (Zhai et al., 2011).

\section{CONCLUSIONS}

Compared with monoculture, the development of superficial roots in mixed stands was optimized, as evidenced by the increase of RLD combined with the slight decrease in RW and RSA. Decease of RSR not only indicated that maize cultivar mixed cropping suppressed root biomass, but also indicated the improvement of shoot biomass, especially under high mixed planting density. However, $\mathrm{Lp}_{\mathrm{r}}$ was improved in mixed cropping systems because of the improvement in root vitality, which allowed for efficient water uptake. Moreover, HI increased significantly in A2B2 and indicated a grain-filling promotion. With a rational allocation between above- and below-ground growth, grain yield and WUE increased by $2.6-15.6 \%$ and $4.7-18.3 \%$ in the mixed systems, compared to monoculture. The distinctive maize cultivar features and their capacity for water and nutrient use largely contributed to plant growth and biomass distribution. Future research on mixed maize cultivars should focus on the responses of mixed cultivars to drought stress, water use and grain production.

\section{ACKNOWLEDGMENTS}

This work was supported by the National High Technology Research and Development Program (863 Program: 2011AA100504) and the National Science and Technology Supporting Programs of China (2015BAD22B01).

\section{Author's contributions}

Xiaolin Wang conducted the experiments, participated in the laboratory experimentation, analyzed the data and wrote the manuscript. Suiqi Zhang designed the experiments. Yinglong Chen gave language editing.

\section{REFERENCES}

Asim, M., M. Akmal and R. Khattak. 2013. Maize response to yield and yield traits with different nitrogen and density under climate variability. J. Plant Nutr. 36: 179-191.

Carvalho, P. and M. Foulkes. 2011. Roots and uptake of water and nutrients. In: Christou, P., R. Savin, B. A. Costa-Pierce, I. Misztal and C. B. A. Whitelaw (Eds.), Sustainable Food Production, Springer, New York.

Cox, W. J. 1996. Whole-plant physiological and yield responses of maize to plant density. Agron. J. 88: 489-496.

Damgaard, C., J. Weiner and H. Nagashima. 2002. Modelling individual growth and competition in plant populations: Growth curves of Chenopodium album at two densities. J. Ecol. 90: 666-671.

Donald, C. M. 1968. The breeding of crop ideotype. Euphytica. 17: 385-403.

Echarte, L., A. D. Maggiora, D. Cerrudo, V. Gonzalez, P. Abbate, A. Cerrudo, V. O. Sadras and P. Calvino. 2011. Yield response to plant density of maize and sunflower intercropped with soybean. Field Crops Res. 121: 423-429.

Fang, Y., B. C. Xu, L. Liu, Y. J. Gu and Q. Q. Liu. 2014. Does a mixture of old and modern winter wheat cultivars increase yield and water use efficiency in water-limited environments? Field Crops Res. 156: 12-21.

Gao, Y., A. Duan, X. Quu, X. Li and U. Pauline. 2013. Modeling evapotranspiration in maize/soybean strip intercropping system with the evaporation and radiation interception by neighboring species model. Agric. Water. Manag. 128: 110-119.

Gong, Z. T., G. L. Zhang and Z. C. Chen. 2007. Pedogenesis and Soil Taxonomy, Beijing Science Press Publication, Beijing.

Hay, R. 1995. Harvest index: A review of its use in plant breeding and crop physiology. Ann. Appl. Biol. 126: 197-216.

Hu, F., Y. Gan, H. Cui, C. Zhao, F. Feng, W. Yin and Q. Chai. 2016. Intercropping maize and wheat with conservation agriculture principles improves water harvesting and reduces carbon emissions in dry areas. Eur. J. Agron. 74: 9-17. 
Jiang, W., K. Wang, Q. Wu, S. Dong and P. Liu. 2013. Effects of narrow plant spacing on root distribution and physiological nitrogen use efficiency in summer maize. Crop J. 1: 77-83.

Ju, X. T., G. X. Xing, X. P. Chen, S. L. Zhang, L. J. Zhang, X. J. Liu, Z. L. Cui, B. Yin, P. Christie, Z. L. Zhu and F. S. Zhang. 2009. Reducing environmental risk by improving $\mathrm{N}$ management in intensive Chinese agricultural systems. Proc. Natl. Acad. Sci. 106: 3041-3046.

Liang, K., T. Yang, S. Zhang, J. E. Zhang, M. Luo, L. Fu and B. Zhao. 2016. Effects of intercropping rice and water spinach on net yields and pest control: An experiment in Southern China. Int. J. Agric. Sustain. DOI: org/10.1080/14735903. 2016.1155391.

Lin, Y., F. Huth, U. Berger and V. Grimm. 2014. The role of belowground competition and plastic biomass allocation in altering plant mass-density relationships. Oikos. 123: 248-256.

Lithourgidis, A. S., C. A. Dordas, C. A. Damalas and D. N. Vlachostergios. 2011. Annual intercrops: An alternative pathway for sustainable agriculture. Aust. J. Crop Sci. 5: 396-410.

Lopez, C. G. and C. C. Mundt. 2000. Using mixing ability analysis from two-way cultivar mixtures to predict the performance of cultivars in complex mixtures. Field Crops Res. 68: 121-132.

Ma, S. C., B. C. Xu, F. M. Li, W. Z. Liu and Z. B. Hang. 2008. Effects of root pruning on competitive ability and water use efficiency in winter wheat. Field Crops Res. 105: 56-63.

Malezieux, E., Y. Crozat, C. Dupraz, M. Laurans, D. Makowski, H. Ozier-Lafontaine, B. Rapidel, S. de Tourdonnet and M. ValantinMorison. 2009. Mixing plant species in cropping systems: Concepts, tools and models. A review. Agron. Sustain. Dev. 29: 43-62.

Mushagalusa, G. N., J. F. Ledent and X. Draye. 2008. Shoot and root competition in potato/maize intercropping: Effects on growth and yield. Environ. Exp. Bot. 64: 180-188.

Kiaer, L. P., I. M. Skovgaard and H. Ostergard. 2012. Effects of intervarietal diversity, biotic stresses and environmental productivity on grain yield of spring barley variety mixtures. Euphytica. 185: 123-138.

Kiaer, L. P., I. M. Skovgaard and H. Ostergard. 2009. Grain yield increase in cereal variety mixtures: A meta-analysis of field trials. Field Crops Res. 114: 361-373.

Palta, J. A., X. Chen, S. P. Milroy, G. J. Rebetzke, M. F. Dreccer and W.
Michelle. 2011. Large root systems: Are they useful in adapting wheat to dry environments? Funct. Plant. Biol. 38: 347-354.

Radicetti, E., R. Mancinelli and E. Campiglia. 2012. The competitive ability of different chickpea (Cicer arietinum) genotypes against Polygonum aviculare under field conditions. Crop Prot. 42: 312-319.

Roose, T. and A. Fowler. 2004. A model for water uptake by plant roots. J. Theor. Biol. 228: 155-171.

Song, L., F. M. Li, X. W. Fan, Y. C. Xiong, W. Q. Wang, X. B. Wu and N. C. Turner. 2009. Soil water availability and plant competition affect the yield of spring wheat. Eur. J. Agron. 31: 51-60.

Smith, D., N. Inman-Bamber and P. Thorburn. 2005. Growth and function of the sugarcane root system. Field Crops Res. 92: $169-183$.

Smith, D. and J. Roberts. 2003. Hydraulic conductivities of competing root systems of Grevillea robusta and maize in agroforestry. Plant. Soil. 251: 343-349.

Sinclair, T. R. 1998. Historical changes in harvest index and crop nitrogen accumulation. Crop Sci. 38: 638-643.

Tetio-Kagho, F. and F. Gardner. 1988. Responses of maize to plant population density. II. Reproductive development, yield, and yield adjustments. Agron. J. 80: 935-940.

Temesgen, A., S. Fukai and D. Rodriguez. 2015. As the level of crop productivity increases: Is there a role for intercropping in smallholder agriculture. Field Crops Res. 180: 155-166.

Xia, H. Y., J. H. Zhao, J. H. Sun, X. G. Bao and P. Christie. 2013. Dynamics of root length and distribution and shoot biomass of maize as affected by intercropping with different companion crops and phosphorus application rates. Field Crops Res. 150: 52-62.

Zajac, T., A. Oleksy, A. Stoklosa, A. Klimek-Kopyra, N. Styrc, R. Mazurek and W. Budzynski. 2014. Pure sowings versus mixtures of winter cereal species as an effective option for fodder-grain production in temperate zone. Field Crops Res. 166: 152-161.

Zhai, L., R. Xie, D. Ma, G. Liu, P. Wang and S. Li. 2011. Evaluation of individual competitiveness and the relationship between competitiveness and yield in maize. Crop Sci. 55: 2307-2318.

Zhang, D. Y., G. J. Sun and X. H. Jiang. 1999. Donald's ideotype and growth redundancy: A game theoretical analysis. Field Crops Res. 61: 179-187. 